\title{
Raman analysis of glaze on various archaeological shard samples and intact Ming plates
}

\author{
LD Kock* \\ Department of Chemistry, University of Pretoria, Pretoria 0002, South Africa ${ }^{\dagger}$
}

\begin{abstract}
Raman microscopy is used in the analysis of glaze on a number of samples that include, blue and white ceramic shards, a tile from the Citadel of Algiers and intact Ming plates. The use of the glaze depth profiling method for the study of interfacial pigments on these samples [J. Raman Spectrosc. 2007; 38: 1480] prompted the study of the glaze on the same set of samples to determine glaze type dependence of this method. Using the index of polymerization $\left(I_{\mathrm{p}}\right)$ which is closely correlated with glaze composition and processing temperature, it is shown that processing temperature could be estimated from a low of about $600{ }^{\circ} \mathrm{C}$ for some of the unknown archaeological shards to about $1000{ }^{\circ} \mathrm{C}$ or above for the Ming porcelain shards. Two intact porcelain plates from the Hongzhi (1488 - 1505) and Wanli (1573 - 1620) Ming imperial periods from the J. A. van Tilburg Museum of the University of Pretoria have been studied and glaze/glass transition temperature was estimated to be above $1000{ }^{\circ} \mathrm{C}$, consistent with historical data. $\mathrm{A} \mathrm{SnO}_{2}$ based glaze tile shard from the Citadel of Algiers was also successfully probed and results indicated a much lower sintering temperature.
\end{abstract}

KEYWORDS: Raman Spectroscopy, Glaze Analysis, Silicate glaze, Index of Polymerization,

\footnotetext{
${ }^{*}$ Correspondence to: L D Kock, ${ }^{\dagger}$ Current address: Applied Chemistry, South African Nuclear Energy Corporation Limited, P.O. Box 582, Pretoria 0001, South Africa. E-mail:

david.kock@necsa.co.za, Tel: +27 12305 6077, Fax: +27 12305 6945.Contract/grant sponsor: University of Pretoria
} 


\section{INTRODUCTION}

Fluorescence in Raman spectroscopy as applied to the study of glazed ceramic artifacts greatly affect the spectral assignment because it can mask spectra collected from the glaze and/or pigments in the sample. Fluorescence in this case emanates from the glaze of the artifacts and is largely attributed to the presence of impurities ${ }^{1}$ and the degree of porosity of the glaze under study. ${ }^{2}$ The use of a confocal set-up in Raman microscopy ensures that mainly the spectrum from the focus point is obtained. ${ }^{3}$ This allows for collection of scattered radiation from volumes in orders of one cubic micron $\left(1 \mu \mathrm{m}^{3}\right)$ at the focus point, thereby discriminating between glaze spectra and that from the interfacial region (glaze/ceramic). ${ }^{4-6}$ This region is usually composed of decorative pigments and other colouring agents which are then detected through the intervening glaze $\mathrm{e}^{4-6}$.

One of the questions that arise pertains to whether distinct ceramic/glaze interfacial pigment spectra so obtained ${ }^{5-6}$ is glaze type dependent. That is, could it depend on glaze composition, microstructure and processing temperature? In this paper, the glazes on which the depth profiling method was successfully applied are analyzed using the Index of polymerization $\left(I_{\mathrm{p}}\right)$ concept in order to answer these questions. The concept of the Index of polymerization $\left(I_{\mathrm{p}}\right)$ is a well documented method developed by Colomban et $\mathrm{al}^{7-}$ ${ }^{10}$ for the analysis of glaze/glass and has also been successfully applied in other laboratories. ${ }^{11-12}$ The information obtained is used to further compare and contrast Ming porcelain artifacts and shards of archaeological origin. The glaze on intact Ming period porcelain plates and a tile from the Citadel of Algiers are also studied and comparisons are made.

Contract/grant sponsor: National Research Foundation 


\section{EXPERIMENTAL}

\subsection{Samples}

The samples used in this study are of various origins, glaze types, glaze thicknesses and are underglaze blue and white ceramic artefacts, except for the multi-coloured tile from the Citadel of Algiers (Figure 1). The pigment on these samples have been studied in depth and the results have been reported. ${ }^{5-6}$ Figure 1 shows the sample set, made up of Ming samples $\mathrm{A}$ and $\mathrm{B}$, unknown samples of archaeological origins $\mathrm{C}, \mathrm{D}$ and $\mathrm{F}$ and sample E of Meissen origin and the Citadel tile (Sample G) and are reproduced here from earlier publications. ${ }^{5-6}$

In addition, the Ming plates (sample $\mathrm{H}$ and I of the Hongzhi (1488 - 1505) and Wanli (1573 - 1620) imperial periods respectively) are also added to the study. The glaze thicknesses were estimated with a $1.0 \mathrm{~mm}$ graduated ruler and the measurements were made on the broken edges where this was possible (shards and tile). Glaze thicknesses were also estimated using the excitation laser excitation beam (Table 1).

The interface was clearly visible through the microscope on the transparent glazes ${ }^{4-6}$ and the thin layer of pigment decoration was used as a guide for the opaque glaze sample. The samples were used as received with no further preparation apart from wiping with methanol to clean the glaze surfaces where necessary. 
Table 1. The table displays glaze thicknesses of the studied samples as determined by direct measurement and by approximate location of the ceramic/glaze interface using the laser beam. Notice that only by using the beam can one determine glaze thicknesses of intact artifacts

\begin{tabular}{|l|l|l|l|l|l|l|l|l|l|}
\hline & Ming A & Ming B & Unknown C & Unknown D & Unknown F & Meissen E & Tile G & $\begin{array}{l}\text { Plate } \\
\text { H(Hongzhi) }\end{array}$ & $\begin{array}{l}\text { Plate I } \\
(\text { Wanli) }\end{array}$ \\
\hline Thickness $(\mathrm{mm})$ & 0.4 & 0.4 & 0.1 & 0.1 & 0.1 & 0.2 & n.d. & - & - \\
\hline Thickness $(\mu \mathrm{m})$ & 450 & 424 & 124 & 128 & 116 & 240 & n.d. & 394 & 420 \\
\hline
\end{tabular}



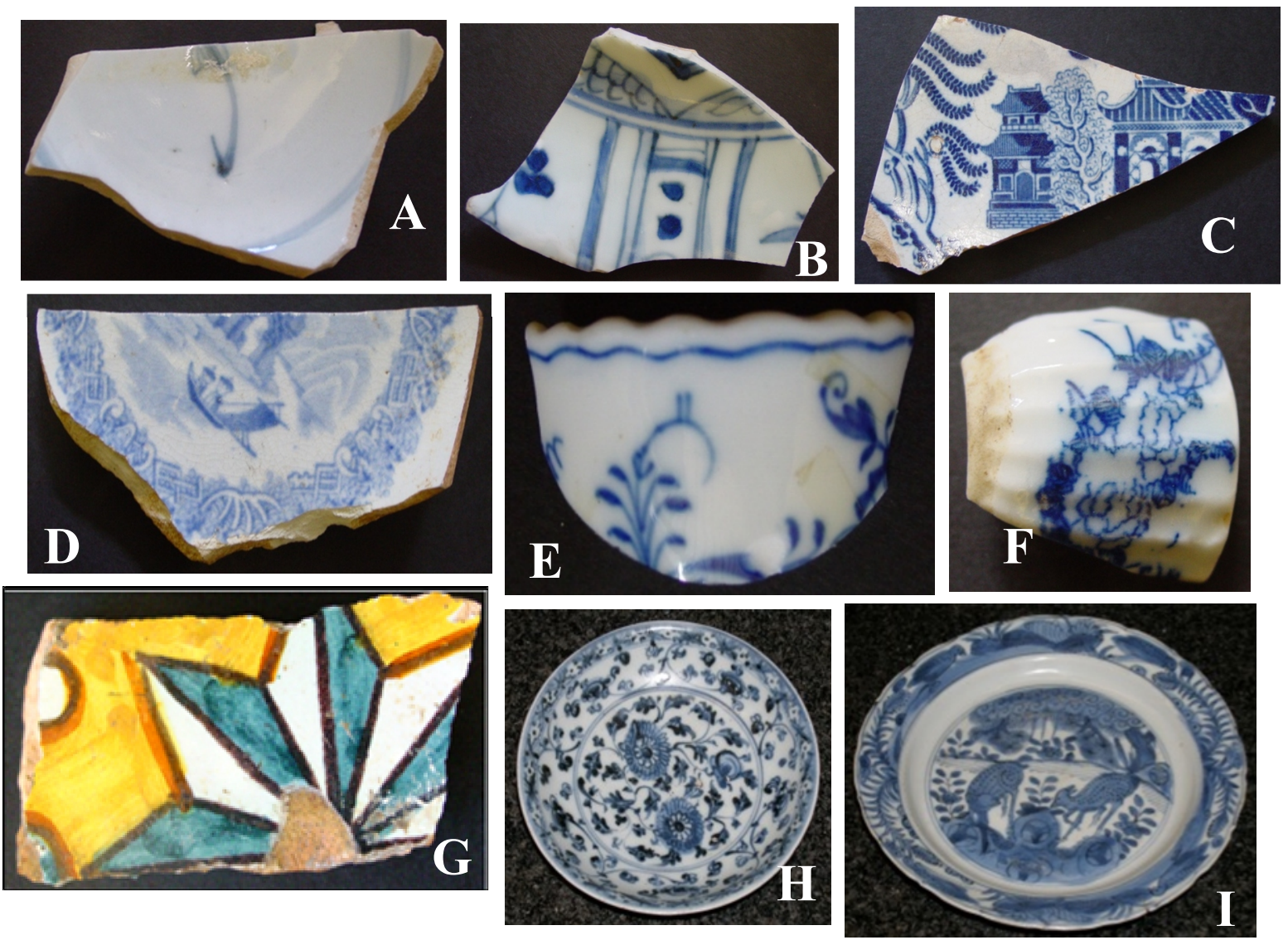

Figure 1. The sets of shards and intact plates that were used for the glaze depth profile studies are shown here. Samples A and B are Ming shards from the National Cultural History Museum (NCHM). Samples C, D and F are archaeological shards of unknown origins from NCHM. Sample E is of Meissen origin while sample G is a tile from the Citadel of Algiers. Samples H and I are intact Ming porcelain plates from the Van Tilburg museum at the University of Pretoria. 


\subsection{Raman and EDX measurements}

A Dilor Raman instrument (Dilor XY multi-channel spectrometer) with a spectral resolution of about $2 \mathrm{~cm}^{-1}$, equipped with a liquid nitrogen-cooled CCD detector was used in the Raman measurements. An Olympus confocal microscope in a $180^{\circ}$ backscattering configuration was attached to the spectrometer. 50X and 100X Olympus long focal length objective lenses were used. Integration times were typically between 120 300 seconds with $2-3$ accumulations in each spectral window for the silicate glazes found on the blue and white porcelain samples, while lower integration times of $100-$ 120 seconds with one accumulation was sufficient to obtain glaze spectra from the $\mathrm{SnO}_{2}$ based glaze.

The excitation radiation was $514.5 \mathrm{~nm}$ wavelength supplied by an Innova 300 argon Iron laser with power set typically at between $0.5 \mathrm{~mW}$ and $40 \mathrm{~mW}$. The laser powers are reported as measured at the sample and the target being the glaze and not the pigment in those samples that may have some pigment exposed to the surface. Data acquisition, baseline corrections and spectra processing were carried out with LabSpec ${ }^{\circledR}$ software (Jobyn Yvon, Horiba Group). Peak fitting was undertaken with the Origin ${ }^{\circledR}$ software (Microcal Software Inc.). EDX measurements were carried out with a JEOL JSM 5800LV scanning electron microscope operated at low vacuum, with an accelerating voltage of $20 \mathrm{kV}$. The use of low vacuum eliminated the need for gold sputtering to enhance surface conductivity. 


\subsection{Peak fitting and data processing}

A method that was developed and used by Colomban and co-workers ${ }^{7}$ was used to analyze glaze on our samples. Spectral treatment and handling outlined by Colomban and coworkers is followed closely to facilitate comparison of results obtained. Basic postulates, related assumptions and results from application of this method can be found in the literature. ${ }^{7,13-18}$

Since the Raman spectra of porcelain glazes is generally dominated by broad bands around $500 \mathrm{~cm}^{-1}$ and $1000 \mathrm{~cm}^{-1}$ that are associated with $v_{2}$ bending vibrations and the coupled $v_{1}$ and $v_{3}$ Si-O stretching vibrations of the isolated tetrahedral respectively, ${ }^{19}$ it is in the latter region (Si-O stretching) that our analysis will be focused. The consideration of a direct relationship between glass formers (example $\mathrm{Si}$ and $\mathrm{Al}$ ) and flux $(\mathrm{Na}, \mathrm{K}, \mathrm{Ca}$, $\mathrm{Pb}$ oxides) content and glass properties has been known ${ }^{7,20-22}$ and follows logically from the established silicate glass structure as a three dimensional polymeric network of $\mathrm{SiO}_{4}$. Any introduction of the flux $(\mathrm{Na}, \mathrm{K}, \mathrm{Ca}, \mathrm{Pb}$ oxides) in the network changes the connectivity of the predominantly $\mathrm{Si}-\mathrm{O}$ bonds in the network as well as the partial ionic charge of the terminal oxygen atoms, hence changes in bond lengths and polarizability ${ }^{7}$ which is a function of Raman activity and may affect the Raman cross section of the various modes in the glass. In the deconvolution of the silicate stretching envelope (ca $700-1300 \mathrm{~cm}^{-1}$ ) one can define five components within this region as $\mathrm{Q}^{o}$ (isolated tetrahedron), $\mathrm{Q}^{l}$ (tetrahedral linked by a common oxygen atom, $\mathrm{Si}_{2} \mathrm{O}_{7}$ ), $\mathrm{Q}^{2}$ (tetrahedral linked by sharing two oxygen atoms, $3 \mathrm{Si}_{3} \mathrm{O}_{9}$ with $\mathrm{n}$-tetrahegral cycles), $\mathrm{Q}^{3}$ (tetrahedra linked by sharing three oxygen atoms) and $\mathrm{Q}^{4}$ (as it appears in pure $\mathrm{SiO}_{4}$ ). ${ }^{8-10,19,23}$ These 
$\mathrm{Q}^{n}$ values are found to have characteristic Raman signatures and should assist in determining the degree of polymerization of the silicate network and hence the type and concentration of the fluxing agents used.

Based on these observations, Colomban and co-workers extracted a relationship between the index of polymerization, $I_{\mathrm{p}}$, and the glaze/glass composition and the processing or glass transition temperature with ample demonstration of this method in the literature ${ }^{8-14}$. This index of polymerization is defined as $I_{\mathrm{p}}=\mathrm{A}_{500} / \mathrm{A}_{1000}$ where $\mathrm{A}$ is the area under the Raman band at the specified wavenumber. ${ }^{16}$ This method of analysis should assist in determining the similarity or lack thereof in the various glaze types on porcelain samples in our possession and therefore glaze type (composition and processing temperature) dependence on the success of the glaze depth profiling method in terms of composition and processing temperature of the glaze through which the underglaze pigments have been studied. Because of the amorphous nature of the silicates that comprise the bulk of the glaze, a Gaussian shape was assumed in the deconvolution processes. ${ }^{3,11}$

\section{RESULTS AND DISCUSSION}

\subsection{Blue and white porcelain glaze}

The raw Raman spectral data that was collected from the glaze surface to the interfacial region of the porcelain samples are shown in figure 2 and 3.

Only the glaze surface spectra of the samples were used in these studies in order to compare the various glazes without pigment interference. It was also found that, 


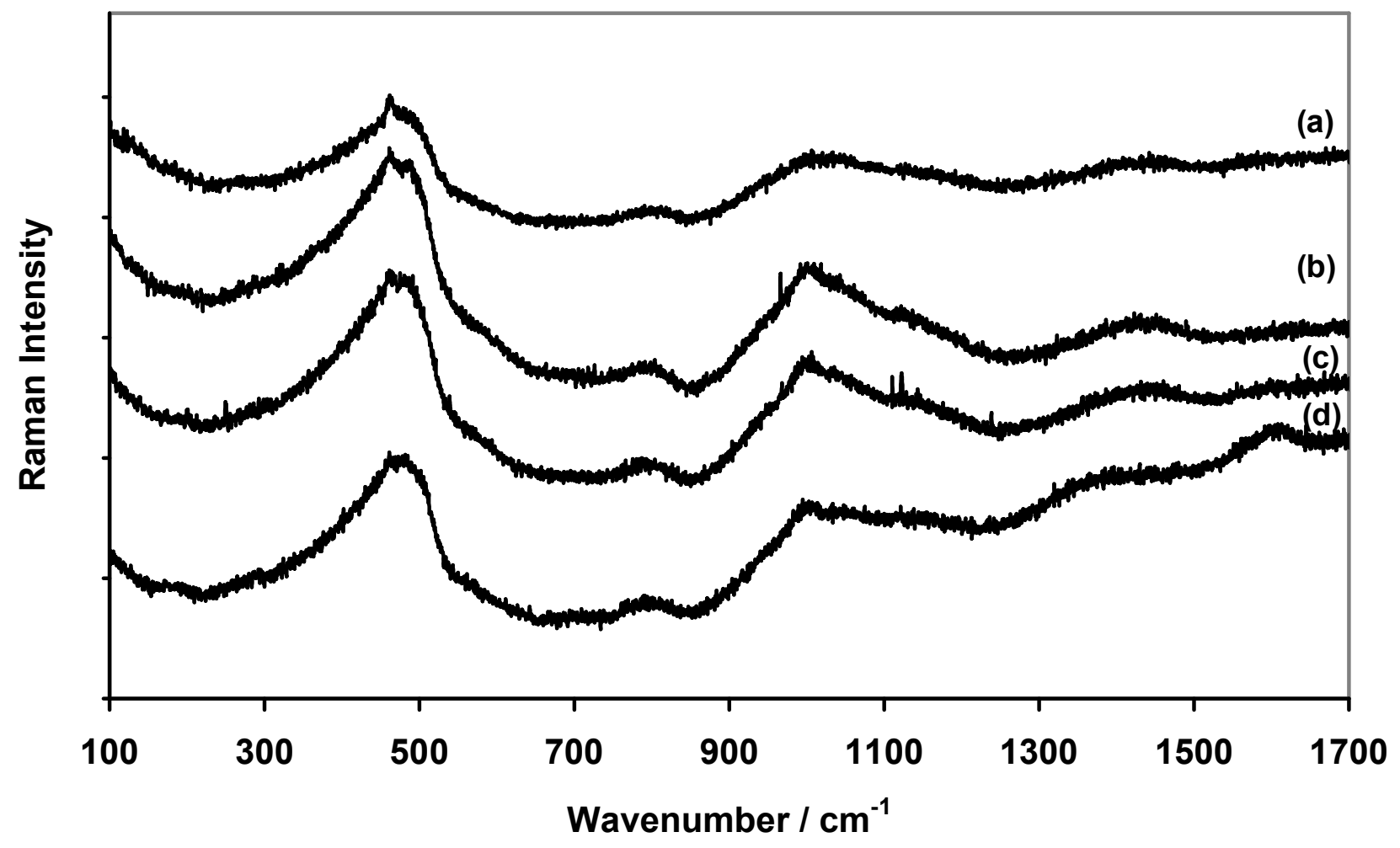

Figure 2. The first four glaze spectra collected on the surface of sample $C$ where the spectrum in (a) represent the surface of the sample and subsequent spectra represent the interior of the glaze. While the surface Figure 2(a) does not show the presence of amorphous carbon, Figure 2(d) shows broad bands between 1300 and $1700 \mathrm{~cm}^{-1}$. 


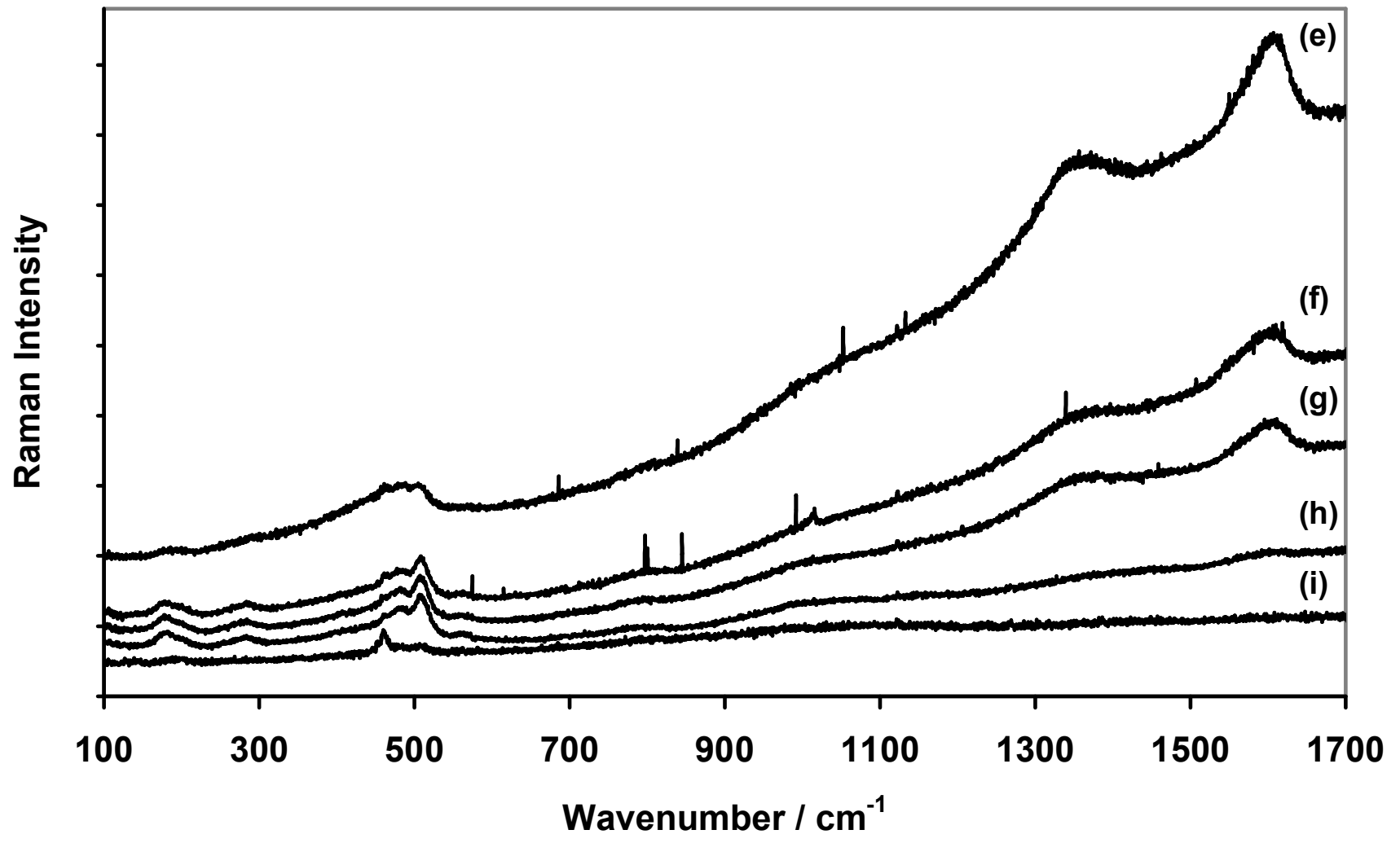

Figure 3. Subsequent spectra in the interior of the glaze towards the glaze/ceramic interface. The interior of the glaze is seen as the origin of more fluorescence activity than the glaze/ceramic interface. This fluorescence is accompanied by the presence of amorphous carbon as seen by broad Raman bands between 1300 and $1700 \mathrm{~cm}^{-1}$. Figure 3(i) also shows a silica band around $460 \mathrm{~cm}^{-1}$ expected to come from the ceramic surface. 
relatively high fluorescence emanated from intact Ming plates (samples H and I) while both the Ming shards (samples A and B) show intermediate and mutually similar relative fluorescence intensities. This is in contrast to the unknown archaeological shards (samples C, D and F) and the Meissen shard (sample E) which showed relatively little fluorescent activity.

Visually, the unknown shards of archaeological and that of Meissen origin show a clear transparent glaze as compared to the Ming porcelain (shards and intact plates) which have a tint of white inside the glaze due to higher density of bubbles in the glaze as observed under the microscope. This high density of bubbles in the glaze qualitatively correlates with increased fluorescence from the respective glaze samples. In this situation, fluorescence is usually attributed to organic or inorganic contaminants in the open pores within the glaze. ${ }^{17}$ Since the high laser powers (up to $30 \mathrm{~mW}$ at the sample) used on these blue and white samples is expected to clean the glaze surfaces of any organic impurities, the relative degree of fluorescence intensity on these samples is most likely due to inorganic impurities, glaze composition and/or microstructure rather than surface borne organic impurities. Organic or inorganic impurities trapped inside the glaze are therefore assumed to be the origin of fluorescence in this case.

The glaze surface spectra shown in figure 2(a) for all samples, were similarly treated by first performing a baseline correction anchored at the same points using LabSpec ${ }^{\circledR}$ software. The same smoothing functions within the same spectral window were used to 
prepare spectra before a Gaussian function was applied in a peak fitting procedure using the Origin ${ }^{\circledR}$ curve fitting software to produce spectra shown in figure 4 .

The extracted data is plotted in Figure 5 with the ratio $I_{500} / I_{1000}$ plotted on the y-axis and sample number as the x-axis. In addition, when percent integrated band area values for the $\mathrm{Q}^{\mathrm{n}}$ modes are plotted against the band centres (wavenumbers), one finds that there is no change in the $\mathrm{Q}^{0}$ mode as expected ${ }^{16}$ since $\mathrm{Q}^{0}$ depends only on the isolated $\mathrm{SiO}_{4}$ tetrahedral units.

Since the polarization index $\left(I_{\mathrm{p}}=\mathrm{A}_{500} / \mathrm{A}_{1000}\right)$ is correlated with the processing temperature and composition of glassy silicates, ${ }^{7,19}$ this parameter was calculated from the Raman signature of the various glaze types and used to predict glaze properties. Differentiation between lead-based and alkali based glaze-types is possible ${ }^{6,9,19}$ while processing temperature determinations follow directly from consideration of the degree of connectivity of the $\mathrm{SiO}_{4}$ polymeric units that are determined from the relative Raman intensities of the Si-O bending $\left(500 \mathrm{~cm}^{-1}\right)$ modes ${ }^{10}$ and is related to the flux content.

The Index of polymerization of the tile sample in Table 2 indicates processing temperatures of just above $600{ }^{\circ} \mathrm{C}$ but far less than $1000{ }^{\circ} \mathrm{C}$.

EDX results confirm glaze type on the tile sample as lead-based mixed enamels $\left(I_{\mathrm{p}}=0.3\right.$ for the tile) in agreement with Raman derived $I_{\mathrm{p}}$ values of between 0.3 and 0.5 for lead rich silicates processed at low temperature $\left(<700{ }^{\circ} \mathrm{C}\right) \cdot{ }^{7,19}$ The unknown samples show a 
Table 2. Centres of gravity as obtained from the deconvolution process of the glaze spectra for the various blue and white samples, including the tile shard and the calculated Index of polymerization $\left(I_{\mathrm{p}}\right)$. The $v \mathrm{Q}^{\mathrm{n}}$ values are indicated in $\mathrm{cm}^{-1}$.

\begin{tabular}{|c|c|c|c|c|c|c|}
\hline Sample & $v Q^{0}$ & $v Q^{1}$ & $v Q^{2}$ & $v Q^{3}$ & $\mathbf{v} \mathbf{Q}^{4}$ & $I_{\mathrm{p}}$ \\
\hline Ming $A$ & 803 & 937 & 1006 & 1061 & 1134 & 1.4 \\
\hline Ming B & 798 & 951 & 1022 & 1089 & 1162 & 2 \\
\hline Unknown C & 794 & 938 & 1007 & 1083 & 1161 & 2.7 \\
\hline Unknown D & 789 & 945 & 1011 & 1093 & 1174 & 2.3 \\
\hline Unknown F & 795 & 939 & 1012 & 1086 & 1166 & 4 \\
\hline Meissen E & 798 & 964 & 1026 & 1093 & 1165 & 1.8 \\
\hline Plate H (Hongzhi) & 782 & 919 & 975 & 1040 & 1118 & 2.1 \\
\hline Plate I (Wanli) & 788 & 946 & 1021 & 1095 & 1184 & 2.4 \\
\hline Tile G & & & & & & 0.3 \\
\hline
\end{tabular}




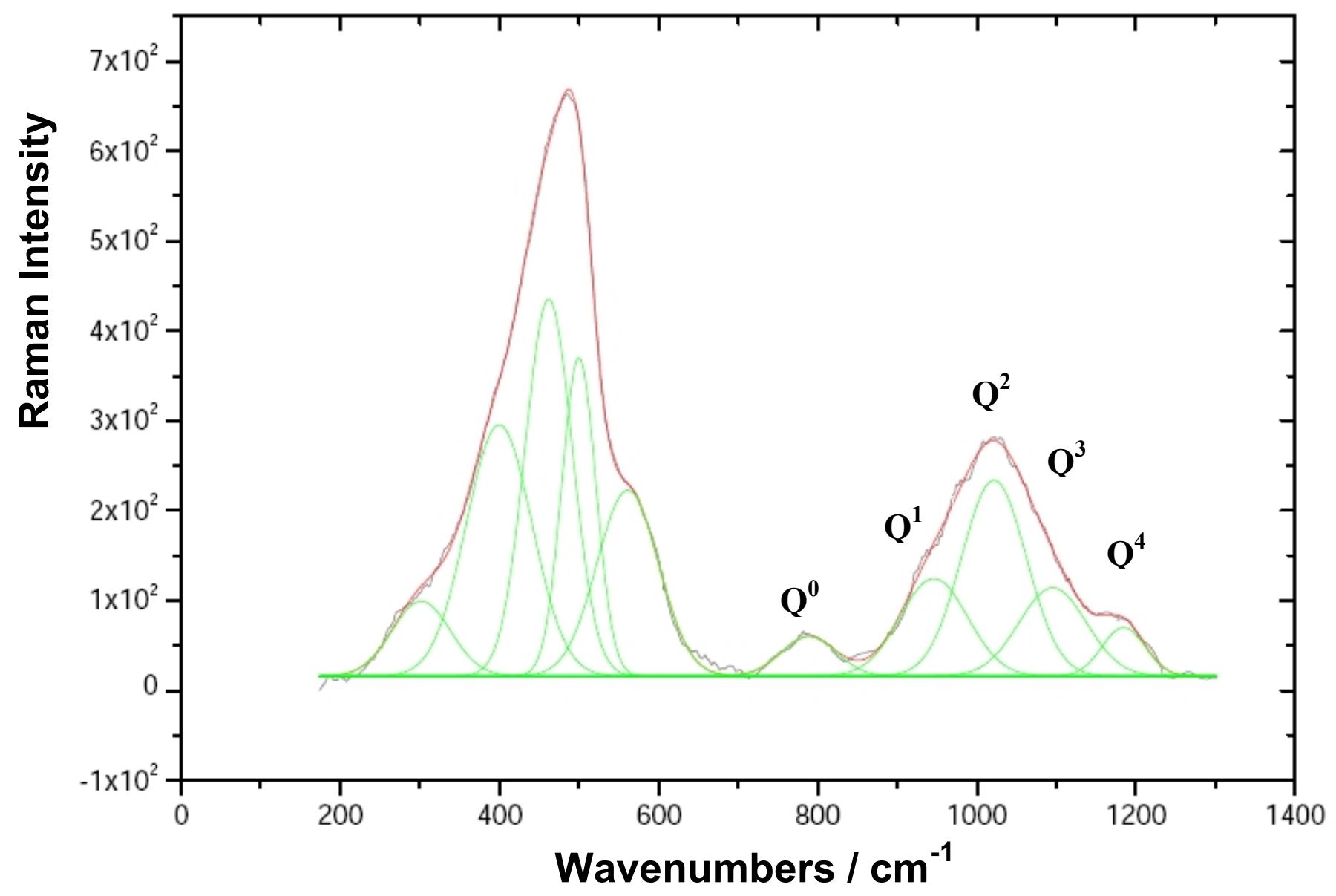

Figure 4. A typical deconvoluted glaze spectra from the various samples from where the $\mathrm{Q}^{\mathrm{n}}$ values are extracted. All samples were treated in the same way for calculation of the Index of polymerization $\left(I_{\mathrm{p}}\right)$ listed in table 2. 
polymerization Index that is between 2.3 and 4 . These glaze types (except sample F) contain lead of up to $18.09 \%$ (Unknown sample D) and $19.03 \%$ (Unknown sample C), alkaline earth metals and alkali metals acting as fluxing agents that lower the glass transition temperature of the glassy networks. ${ }^{7,10}$ On the other hand, the Ming samples (Samples A, B, H and I) show $I_{\mathrm{p}}$ values that lie between 1.4 and 2.4 corresponding to Cabased glazes ${ }^{7,10,23}$ with glass transition temperatures of about $1000{ }^{\circ} \mathrm{C}$ or above. Again, EDX results confirm the dominance of $\mathrm{Ca}$ over $\mathrm{Pb}$ in these Ming samples (only shards samples and not intact plates were used in the EDX studies (Table 3).

The Meissen sample (E) with $I_{\mathrm{p}}$ of 1.8 also corresponds to a Ca-based glaze (Pb-poor) with an estimated glass transition temperature of about $1000{ }^{\circ} \mathrm{C}$ or above. This family of glassy silicates show index of polymerization in the range, $1.3<I_{\mathrm{p}}<2.5$. Table 3 shows EDX determined compositions that are consistent with this finding for the Meissen shard. These results are also consistent with other Meissen porcelain studies ${ }^{23}$.

\subsection{Citadel tile glaze}

A detailed study of pigments on the Citadel tile was undertaken and the results have been published. ${ }^{6}$ However, in the same way that a glaze depth profile was generated for the blue and white porcelain silicate glazes, a similar glaze depth profile could be generated for the tile glaze. The glaze depth profile spectra of the top $50 \mu \mathrm{m}$ generated on the white background of the Citadel tile are reported. ${ }^{6}$ Even on this tile with significant amount of $\mathrm{SnO}_{2}$ used in the glaze as an opacifier, the Index of polymerization $\left(I_{\mathrm{p}}\right)$ show this glaze as a $\mathrm{Pb}$ based silicate glaze and therefore low temperature fired sample. EDX elemental 
Table 3. The Table displays EDX data with the main elements in the glaze of the selected samples. The data is not converted to oxides. The relative amounts are apparent from the weight percent.

\begin{tabular}{|c|c|c|c|c|c|c|c|c|c|}
\hline Element (Wt\%) & Ming A & Ming B & Unknown C & Unknown D & Unknown F & Meissen E & Tile $\mathbf{G}$ & Plate H & Plate I \\
\hline $\mathrm{Na}$ & 0.15 & 1.03 & 0.99 & 0.83 & 1.06 & 0.64 & 0.14 & n.d. & n.d. \\
\hline Mg & 0.23 & 0.07 & 0.56 & 0.29 & 0.07 & 1.05 & 0.2 & n.d. & n.d. \\
\hline $\mathrm{Al}$ & 9.74 & 8.8 & 8.41 & 8.53 & 7.86 & 11.32 & 2.01 & n.d. & n.d. \\
\hline Si & 57.97 & 62.49 & 52.64 & 47.98 & 66.52 & 64.16 & 28.5 & n.d. & n.d. \\
\hline $\mathbf{K}$ & 8.49 & 9.7 & 7.52 & 5.99 & 12.73 & 7.28 & 3.7 & n.d. & n.d. \\
\hline $\mathrm{Ca}$ & 20.32 & 14.52 & 8.3 & 16.89 & 6.32 & 12.86 & 0.65 & n.d. & n.d. \\
\hline $\mathbf{P}$ & 0.09 & 0 & 0.1 & 0.11 & 0.07 & 0.18 & 0.09 & n.d. & n.d. \\
\hline $\mathbf{S}$ & 0 & 0 & 0 & 0 & 0 & 0 & 0 & n.d. & n.d. \\
\hline $\mathrm{Cl}$ & 0.27 & 0.11 & 0 & 0.07 & 0.09 & 0 & 0.12 & n.d. & n.d. \\
\hline $\mathrm{Ti}$ & 0.35 & 0.16 & 0.38 & 0.3 & 0.09 & 0.13 & 0.07 & n.d. & n.d. \\
\hline $\mathrm{Fe}$ & 2.24 & 3.08 & 1.54 & 0.59 & 1.89 & 2.38 & 0.44 & n.d. & n.d. \\
\hline Co & 0.15 & 0.03 & 0.52 & 0.34 & 0 & 0 & 0 & n.d. & n.d. \\
\hline $\mathbf{P b}$ & 0 & 0 & 19.03 & 18.09 & 3.35 & 0 & 52.71 & n.d. & n.d. \\
\hline Sn & n.d. & n.d. & n.d. & n.d. & n.d. & n.d. & 9.78 & n.d. & n.d. \\
\hline
\end{tabular}


analysis results (Table 3) also confirm the dominance of $\mathrm{Pb}$ in the sample. Conceivably, one would imagine tiles of this nature to have been fired in large quantities at low temperature during the construction of the Citadel of Algiers.

\section{CONCLUSION}

The glaze types on all blue and white ceramic samples studied in this work indicate that although they range from $\mathrm{Ca}$-based to $\mathrm{Pb}$-dominated glaze types with glass transition temperatures ranging from high $\left(\sim 1000{ }^{\circ} \mathrm{C}\right.$ or above $)$ to low $\left(\sim 600{ }^{\circ} \mathrm{C}\right)$ respectively as estimated through the use of Index of polymerization concept, they could all be studied successfully by the depth profiling method. The $\mathrm{SnO}_{2} / \mathrm{SiO}_{2}$ dominated glaze type of the tile shard from the Citadel of Algiers was also successfully probed using this method. The results indicate that, first, the method does not depend on the type of glaze for the samples under study. Second, there is no evidence of interfacial pigment spectral changes due to glaze composition, morphology etc for the samples under study.. However, it must be noted that this aspect may be explored in a more controlled study where sample composition, morphology, sintering temperatures etc. are well known and controlled to answer this question fully and conclusively. However, these results further support the conclusions reached in our earlier study [J. Raman Spectrosc. 2007; 38: 1480] that the two sets of shards (Ming and Archaeological) are not likely to have a common origin. The consistency of these results from EDX and Raman glaze signature studies also point to the utility and wide applicability of the concept of the Index of polymerization $\left(I_{\mathrm{p}}\right)$ for silicate based glass/glaze analyses. 


\section{ACKNOWLEDGEMENTS}

The University of Pretoria, The National Research Foundation (Financial) and Ms Corine Meyer (Ming shards), Mr. Anton Pelser and Mr. Frank Teichert (Archaeological shards of unknown origin) of the National Cultural History Museum are gratefully acknowledged. Ms Deniz Erduman of the Museum fur Angewandte Kunst, Frankfurt am Main in Germany for providing the Meissen sample, Prof AE Duffey of the J. A. Van Tilburg museum at the University of Pretoria is recognized for releasing the rare intact Ming porcelain plates for study. Andre Botha is acknowledged for assisting with the EDX measurements and Dineo Z Kock for correcting the manuscript.

\section{REFERENCES}

1. I. Osticioli, A. Zoppi, M. Castelluci, J. Raman Spectrosc. 2006; 37, 974

2. Ph. Colomban, Mater. Res. Soc. Symp. Proc. 2005; 852E, 008.4.1.

3. P.V. Huong, Vibrational Spectrosc. 1996; 11, 17.

4. H.G.M. Edwards, Ph. Colomban, B. Bowden, J. Raman Spectrosc. 2004; 35, 656.

5. L.D. Kock, D. de Waal, J. Raman Spectrosc. 2007; 38, 1480.

6. L.D. Kock, D. de Waal, Spectrochim. Acta. 2008; 71A, 1348.

7. Ph. Colomban, A. Tournie, L. Bellot-Gurlet, J. Raman Spectrosc. 2006; 37, 841.

8. Ph. Colomban, V. Milande, H. Lucas, J. Raman Spectrosc. 2004; 35, 68.

9. Ph. Colomban, J Non-Cryst. Solids. 2003; 323, 180.

10. Ph. Colomban, G. March, L Mazerolles, T. Karmous, N. Ayed, A. Ennabli, H. Slim, J. Raman Spectrosc. 2003; 34, 205. 
11. L.C. Prinsloo, N. Wood, M. Loubser, S.M.C. Verryn, S. Tiley, J. Raman Spectrosc. 2005; 36, 806.

12. N. Ollier, T. Charpentier, B. Boizot, G. Wallez, D. Ghaleb, J. Non-Cryst. Solids. 2004; 341, 26.

13. Ph. Colomban, N.Q. Liem, G. Sagon, H.X. Tinh, T.B. Hoành, J. Cult. Heritage $2003 ; 4,187$.

14. Ph. Colomban, V. Milande, L. Le Bihan, J. Raman Spectrosc. 2004; 35, 527.

15. Ph. Colomban, C. Truong, J. Raman Spectrosc. 2004; 35, 195.

16. L.C. Prinsloo, Ph. Colomban, J. Raman Spectrosc. 2008; 39, 79.

17. Ph. Colomban, O. Paulsen, J. Am. Ceram. Soc. 2005; 88, 390.

18. Ph. Colomban, G. Sagon, L.Q. Huy, N.Q. Liem, L. Mazerolles, Archeometry. 2004; 46, 125.

19. N.Q. Liem, N.T. Thanh, Ph. Colomban, J. Raman Spectrosc. 2002; 33, 287.

20. J.M. Stevels, Philips Technical Review, 1960-1961; 22, 300.

21. M.L. Huggins, K.H. Sun, J. Am. Ceram. Soc. 1943; 26, 4.

22. M.B. Volf, Technical Glasses. Pittman: London, 1961.

23. Ph. Colomban, F. Treppoz, J. Raman Spectrosc. 2001; 32, 93. 


\title{
Graphical Table of Contents
}

\section{Raman analysis of glaze on various archaeological shard samples and intact Ming plates}

\author{
L.D. Kock ${ }^{*}$
}

The glaze on archaeological shards and those of Ming dynasty origin have been studied using the Index of polymerization $\left(I_{\mathrm{p}}\right)$ and results confirm that the two sets of shards are not likely to be of the same origin. The glaze depth profiling method is independent of the type and composition of the glaze, and that the concept of the Index of polymerization is of great utility in the study of silicate based glazes/glasses.

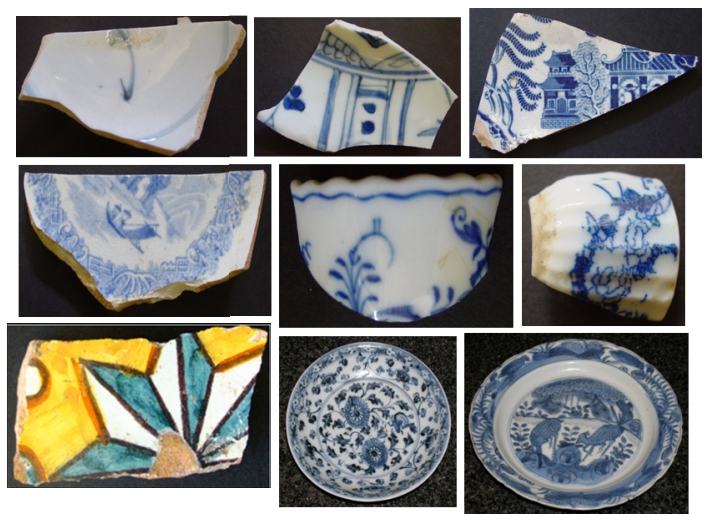




\section{Highlights}

\section{Raman analysis of glaze on various archaeological shard samples and intact Ming plates}

\section{L.D. Kock ${ }^{*}$}

- The glaze depth profiling method using confocal microscopy is independent of glaze/glass type and composition.

- Comparison of archaeological shards and those of Ming origin reveal that the shards are not of the same origin.

- The concept of Index of polymerization is of wide and great utility in the analysis of glaze/glass of wide composition. 